\title{
Research and Application on Bed Material Preparation System of CFB Boiler
}

\author{
Huang Shuzhen ${ }^{1,2}$, Li Xinsheng ${ }^{1,2}$ \\ ${ }^{1}$ Beijing Guodian Futong Science and Technology Development Co., Ltd., Beijing, China \\ ${ }^{2}$ Beijing Engineering Research Center of Pneumatic Conveying, Beijing, China
}

Email address:

huangshuzhen@sgepri.sgcc.com.cn (Huang Shuzhen), lixinsheng@sgepri.sgcc.com.cn (Li Xinsheng)

\section{To cite this article:}

Huang Shuzhen, Li Xinsheng. Research and Application on Bed Material Preparation System of CFB Boiler. International Journal of Energy and Power Engineering. Vol. 9, No. 6, 2020, pp. 108-114. doi: 10.11648/j.ijepe.20200906.13

Received: December 7, 2020; Accepted: December 22, 2020; Published: December 31, 2020

\begin{abstract}
This paper introduces a technology of preparing bed material with bottom slag of circulating fluidized bed boiler, and designs the system of filling the bed material into the furnace, which has been applied in engineering. This technology uses bottom slag to prepare bed material. Through screening treatment of developed ultra-fine roller screen, the bed material with particle size meeting combustion requirements is prepared and fed into fluidized bed furnace. It not only ensures the combustion effect of the boiler, but also saves a lot of bed material procurement and operation costs, at the same time, it reduces the discharge of boiler bottom slag, which is conducive to reducing pollutant emission. Moreover, some limestone which is not involved in the desulfurization reaction in the furnace is screened out and returned to the furnace again as bed material, so as to improve the utilization rate of limestone powder. The success of this system in engineering application provides a low-cost and reliable new bed material preparation and filling method for the industry, and provides a reliable guarantee for the combustion of CFB boilers. The system meets the requirements of energy conservation and environmental protection, enriches the auxiliary system of CFB boiler, improves the supporting level of auxiliary system of CFB boiler, and further promotes the application of clean combustion fluidized bed unit.
\end{abstract}

Keywords: Bed Material, Bottom Slag, Bed Materials Feeding System, Ultra-fine Roller Screen, Energy Conservation and Environmental Protection

\section{Introduction}

With the increasing consumption of energy in society, it is more and more important to solve the problem of environmental pollution in energy production process. At the same time, the emission of waste (ash, flue gas) from thermal power plant and its treatment have been one of the main factors that perplex the cost of power generation. Professional workers have made various efforts to reduce the emission of pollutants in flue gas of coal-fired power plants. Circulating fluidized bed boiler instead of traditional coal-fired boiler is a way to reduce pollution. $\mathrm{CaO}$ and $\mathrm{MgO}$ produced by calcination of limestone in furnace react with sulfide $\left(\mathrm{SO}_{2}\right)$ in fuel to form stable sulfate, so as to reduce sulfide emission in circulating fluidized bed boiler. The low-temperature combustion technology of circulating fluidized bed can also reduce the formation of nitrogen oxides (NOx), thus reducing the emission of nitrogen oxides.
Circulating fluidized bed boiler adopts fluidized combustion technology, which has the following characteristics: gas mixes high-temperature bed material and fuel particles together and fluidizes; convective heat transfer between bed material and fuel forms a low-temperature, staged combustion. The results show that the combustion temperature of fluidized bed boiler is low $\left(850 \sim 900^{\circ} \mathrm{C}\right)$, the emission of Nitrogen Oxides is low, the fuel adaptability is wide, the combustion efficiency is high, the desulfurization cost is low, and the load regulation ratio is large. It makes fluidized bed a clean combustion mode with high efficiency and low pollution. Circulating fluidized bed boiler technology has developed rapidly in recent years. According to statistics, there are about 3100 circulating fluidized bed boilers put into use by various enterprises in our country. The total installed capacity exceeds 73795 MW [1], which ranks the first in the world [2]. Recently, the research of circulating fluidized bed units with large capacity and high parameters 
has been carried out [3]. Accordingly, the research on the ancillary system (equipment) matching the fluidized bed boiler and the coordination between auxiliary systems are also actively carried out, such as the successful development of large-scale model drum-type slag cooling machine.

In the combustion process of circulating fluidized bed boilers, bed material is an important part of fuel combustion. The bed material preparation and bed material adding system are important auxiliary systems of fluidized bed boilers. There are two ways to fill bed materials: filling pre-start and filling during operation, which play the role of establishing bed pressure and adjusting bed pressure respectively. Adjusting bed pressure is one of the methods of adjusting combustion in circulating fluidized bed boiler. Adding bed material in operation can adjust bed temperature and control combustion, thus reducing the emission of Nitrogen Oxides [4]. The combustion of circulating fluidized bed boilers has strict requirements on the particle size of bed materials, and that the particle size is too large or too small will affect the economic operation and safe operation of the boiler [5]. According to the requirements of the boiler plant, if the quartz sand is used as the bed material, the particle size should be less than $1 \mathrm{~mm}$; if the bottom slag is used, the particle size should be less than $3 \mathrm{~mm}$.

\section{Current Situation of Fluidized Bed Material and Filling System}

At present, there are few studies on bed material preparation, bed filling system and equipment, and the bed material as well as its particle size has great influence on the combustion of fluidized bed boiler [6] and wear in furnace [7]. There are two methods to fill the bed material: mechanical and pneumatic conveying methods. The fault of the mechanical filling system is that the arrangement is difficult, it is easy to leak in the operation, and the wear is serious. The pneumatic filling system is very easy to be blocked and wear, so the reliability of the system is greatly reduced. Therefore no matter whether mechanical or pneumatic filling system is applied, the reliability is not satisfactory. At present, the bed material filling system (especially before startup with a large number of centralized filling) generally uses a relatively primitive artificial method. The artificial filling system is inefficient and time-consuming, and it will cause local environmental pollution during the filling process, which affects the health of the workers [8].

At present, quartz sand is often used as bed material (particle size is less than $1 \mathrm{~mm}$ ). Quartz sand bed material needs to be purchased separately, which makes the purchase cost of the bed material increase. When the bed material is added to the boiler, the operation cost is high and the reliability is poor, regardless of the filling method of manual, pneumatic or mechanical.

In order to solve the problem of high purchasing cost of bed materials, the bottom ash and bottom slag of CFB boiler are recommended to be used to fill into the fluidized bed as bed material.

The advantage of bottom slag used as bed material is that the bed material is finer and can be filled by pneumatic conveying method. The shortcoming is that the fine particles are not only easily entrained by the flue gas into the separator in the boiler, increasing the circulation in the boiler, and the fine particles will be taken away from the flue gas from the outlet of the separator and increase the wear and tear of the heated surface. Furthermore, if the ratio of primary air to secondary air is inappropriate, the entrapment effect will be increased for the fine particle size of the bed material, so that a large number of incomplete combustion fuel particles are taken away by the flue gas, the carbon content of fly ash will be increased, and the combustion economy will be reduced [9].

There are two ways to treat the bottom slag as bed material: the first one is that the bottom slag is not treated directly as the bed material, so the oversize sediment particles (especially when the particle size is more than $10 \mathrm{~mm}$ ) are added to the boiler, the more the large particle bed material will accumulate, on the one hand, influence the fluidization of the whole bed and even cause the dead bed; on the other hand, the accumulation of heat capacity will cause the hidden danger of coking. The second kind of bottom slag used as bed material is to grind the bottom slag fine and use it as bed material. This method effectively avoids the aggregation of large granular bed material. However, the disadvantage is that it needs to configure grinding, collecting system and equipment, which makes the bed material preparation and filling system complex. The characteristics of bed material prepared after grinding bottom slag fine and its influence on boiler refer to the influence of bottom ash on the bed materials preparation which is described above.

\section{Development of Preparation Equipment for Bed Material}

Because slag is the solid waste in power plant, it is difficult to handle and takes time. Especially the bottom slag with desulfurizer added in the furnace has low comprehensive utilization value because of its high limestone or Calcium Oxide content. If the part of the slag whose particle size meets the requirements of bed material could be separated, it can not only save the purchasing cost of the quartz sand bed material, but also reduce the discharge of the solid waste of the boiler

\subsection{Characteristic of Bottom Slag}

The sample and particle size analysis of two circulating fluidized bed boiler power plants in Hebei are carried out. The appearance of bottom slag is mostly granular and very few of them are flaky structures. From table 1, it can be seen that the particle size of the bed slag particle size less than $3 \mathrm{~mm}$ accounts for about $80 \%$ of the bottom ash. The amount of bed material can be guaranteed by separating the bottom slag less than $3 \mathrm{~mm}$. The boiler bottom slag is treated as the qualified 
bed material, which provides a new method of energy saving

boiler bed material and its filling system. and environmental protection for the circulating fluidized bed

Table 1. The particle size analysis of boiler slag.

\begin{tabular}{llll}
\hline Item & & Fluidized-bed slag in Hebei A plant /\% & Fluidized-bed slag in Hebei B plant /\% \\
\hline & $\geq 10 \mathrm{~mm}$ & 6.52 & 2.14 \\
& $\geq 8 \mathrm{~mm}$ & 8.81 & 5.08 \\
& $\geq 6 \mathrm{~mm}$ & 14.04 & 10.50 \\
Slag particle size & $\geq 3.2 \mathrm{~mm}$ & 21.44 & 17.30 \\
analysis & $\geq 2 \mathrm{~mm}$ & 33.40 & 26.18 \\
& $\geq 1 \mathrm{~mm}$ & 46.10 & 35.89 \\
& $\geq 0.56 \mathrm{~mm}$ & 60.68 & 48.36 \\
& $\geq 0.3 \mathrm{~mm}$ & 71.41 & 59.87 \\
Bulk density $/\left(\mathrm{kg} \cdot \mathrm{m}^{-3}\right)$ & 1394 & 1240 \\
\hline
\end{tabular}

The key of using bottom slag to prepare bed material is to prepare the bed material - to screen the boiler bottom slag. In order to ensure civilized production, no dust overflow, noise and environmental protection in screening process are required. In the mainstream screening equipment, the characteristics of the screening equipment, such as the fixed screen, the drum screen and the roller screen, are compared and analyzed. Vibrating screen and drum screen are both fixed screen mesh structure. In the screening process, they are easily blocked by the screen holes, which can cause the low screening efficiency and even cause the failure of the screening. In contrast, the roller screen has the characteristics of small size, small vibration, and the sieve hole not easy to block, so it can meet the requirements of civilized production [10].

At present, the application of roller screen is mostly used in raw coal system of thermal power plant, and the particle size of screening is $25 \mathrm{~mm}$. Roller sieve with sieving particle size less than $3 \mathrm{~mm}$ has not been applied yet. Therefore, it is necessary to redesign a kind of ultra-fine roller sieve to meet the requirements of preparing bed materials and screening with small particle size.

\subsection{Design of Ultra-fine Roller Screen}

The roller screen is to use multiple rotating shafts and fixed on the shafts of the screen to rotate with the shafts, to promote the material forward, while fine particles fall into the screen through the slots in the screen. Many shafts and plates of the roller screen are arranged in parallel to form an inclined screen surface. The shafts rotate in the same direction as the material flow through the motor and transmission mechanism, and the plate with openings is driven to rotate by the screen shafts [11]. The material that needs to be screened fluctuates on the screen surface under the action of gravity and screen stirring. Fine particles are screened out through the mesh gap, and large particles are discharged after reaching the end of the screen surface. The movement of the screen plates has the advantages of loosening the material and promoting fine particles to pass through the screen. It is also conducive to cleaning up the particles plugged in the mesh gap, thereby eliminating the blockage of the screen. The particle size after screens can be controlled by the sieve spacing.

The design of ultra-fine roller screen needs the support of bottom slag physical parameters. The sliding angles of CFB boilers bottom slag in the two power plants are tested experimentally. Sliding angle tests were carried out on three different planes for two kinds of bottom slag: ordinary steel plate, $1 \mathrm{~mm}$ slot grid and $4 \mathrm{~mm}$ slot grid. The test results are shown in Table 2.

Table 2. The sliding angle of furnace slag.

\begin{tabular}{lll}
\hline Test item & Fluidized-bed slag in Hebei A plant & Fluidized-bed slag in Hebei B plant \\
\hline sliding angle of the ordinary steel plate $/\left(^{\circ}\right)$ & 24.5 & 22.5 \\
sliding angle of 1mm gap grid $/\left(^{\circ}\right)$ & 29.8 & 29.2 \\
sliding angle of 4mm gap grid $/\left(^{\circ}\right)$ & 32.6 & 31.9 \\
\hline
\end{tabular}

From the test results, it can be seen that the sliding angles of the two kinds of bottom slag are similar, that is, the friction coefficient is equal; the size of the mesh gap has an effect on the sliding angle of bottom slag, and the sliding angle of the mesh with large gap is larger. The main reason is that the small particles on the mesh pass through the cracks, which lack the lubrication between the large particles and the contact surface. Sliding angle of CFB boiler bottom slag on 4 $\mathrm{mm}$ slot grids is about $32^{\circ}$.
According to the analysis of slag particle size and the test of sliding angle and other parameters, the ultra-fine roller screen is designed in combination with the design method of roller screen and the design experience of roller screen applied in fuel system of power plant [12]. The design focus is on the problems of screen angle, structure and shape, material and wear-resistant life of the bottom slag fine screen equipment.

Through the force analysis of the material on the screen 
surface, considering the parameters such as the gravity of the bottom slag, the stirring power of the screen, and the friction of the bottom slag, the angle of the roller screen surface is determined on the premise of ensuring that the bottom slag passes through the screen surface smoothly. The screen plate of the roller screen is designed as a comb structure. The screen plate passes through the grid twice in every rotating cycle, and clears the gap of the grid once in each passing. So the particles jammed in the gap of the grid are cleared by the screen at any time to ensure that it is not blocked. In order to meet the requirements of sieving bottom slag particle size less than $3 \mathrm{~mm}$, according to the design principle of $75 \%$ sieving size and sieve hole ratio, the gap of the screen is designed to be $4 \mathrm{~mm}$ and the thickness of the screen is $3 \mathrm{~mm}$. The wear-resistant material is selected and the surface is treated to ensure the service life of the screen [13]. The cross-section of screen is very thin, so the clearance is required highly. In the process of making and assembling the screen, the quality procedures of processing and installation should be strictly controlled to ensure that each screen is located in the middle of the mesh gap and that there is a gap of $0.5 \mathrm{~mm}$ on each side, so as to ensure the safe operation of the equipment.

After the design is completed, the bottom slag screening test of the ultra-fine roller sieve prototype is carried out. The experimental results show that the particle size of bed material less than $3 \mathrm{~mm}$ after sieving is over $95 \%$, and the sieving equipment has small size, small space required for layout, stable operation, low noise, no plugging, no blocking in sieve hole, reliable sieving particle size, and achieves the design goal.

\section{Design and Application of Bed Material Filling System}

\subsection{Bed Feeding System}

The purpose of the bed material filling system should be: simple system, compact layout, closed links or interfaces, to ensure that the whole process of the system does not leak, and the operation process meets the requirements of environmental protection. The design of filling system should be also combined with the form and layout characteristics of boiler slag removal system.

Taking the mechanical slag conveying system as an example, a simple and practical bed material preparation and filling system is designed. The technological process of mechanical slag conveying system is as follows: bottom slag $\rightarrow$ slag cooler scraper $\rightarrow$ conveyor (or spiral conveyor) $\rightarrow$ bucket elevator $\rightarrow$ slag storage $\rightarrow$ automobile transportation. After researching the process of mechanical slag removal system, the screening equipment is set at the outlet of bucket elevator and forms a large height difference between screening equipment and filling port, which will be convenient for the arrangement of subsequent bed material buffer hopper and filling equipment and the selection of the simplest way to enter furnace.

A switch valve is installed at the outlet of the bucket elevator of the mechanical slag conveying system, which divides the bottom slag of the bucket elevator into two routes, one directly into the slag silo for storage and transportation, the other into the roller screen for screening and preparing bed materials. When there is no need to prepare the bed material, the switch valve turns to the direction of the slag silo, and the bottom slag enters the slag silo directly according to the original design. When the bed material needs to be prepared, the switch valve turns to the direction of bed material preparation, and the bottom slag enters the ultra-fine roller screen for screening and screening. After screening the large particles through the screen surface, they enter the slag silo through the slag discharge tube. The fine particles with size less than $3 \mathrm{~mm}$ fall under the screen after through the mesh, and fall into the bed material buffer hopper (bed material tank) through the discharge tube, then become the bed material with qualified particle size. When the bed material needs to be added in the operation of the boiler, the bed material temporarily stored in the buffer hopper (bed material tank) is pneumatically fed into the furnace.

The switch valves are used at the outlet of bucket elevator, and are operated remotely by hand, which make the preparation bed material system flexible and convenient to put into operation or stop. The equipment and its connection in the bed material preparation and filling system are all in a fully sealed state, which avoids leakage and dust raising, and meets the requirements of environmental protection. Pneumatic conveying is adopted for conveying bed material into furnace, and its pipeline is designed as DTS (Double Socket Tube) type [14], which can effectively prevent pipe blockage failure of conveying pipeline and guarantee its operation reliability.

For the screen plate material, ceramic material is selected, which has the advantages of high hardness, high wear resistance and oxidation resistance [15]. The material not only ensures the service life of the screen plate, but also improves the processing reliability of the thin section screen plate, further ensures the reliability of the bed material filling system and improves the practicability of the system.

\subsection{Application of Bed Feeding System}

After the successful development of the bed material preparation and filling system for bottom slag, an engineering application was carried out in a factory in Zhejiang Province. The boiler of this plant is a $450 \mathrm{t} / \mathrm{h}$ CFB boiler of Foster Wheeler Company. The boiler is equipped with high temperature and pressure, natural circulation single steam drum, single furnace, balanced ventilation and open-air arrangement. The slag discharge mode is solid slag discharge. In order to improve combustion efficiency and stabilize bed pressure, the boiler needs to prepare and feed bed materials according to operation conditions. 


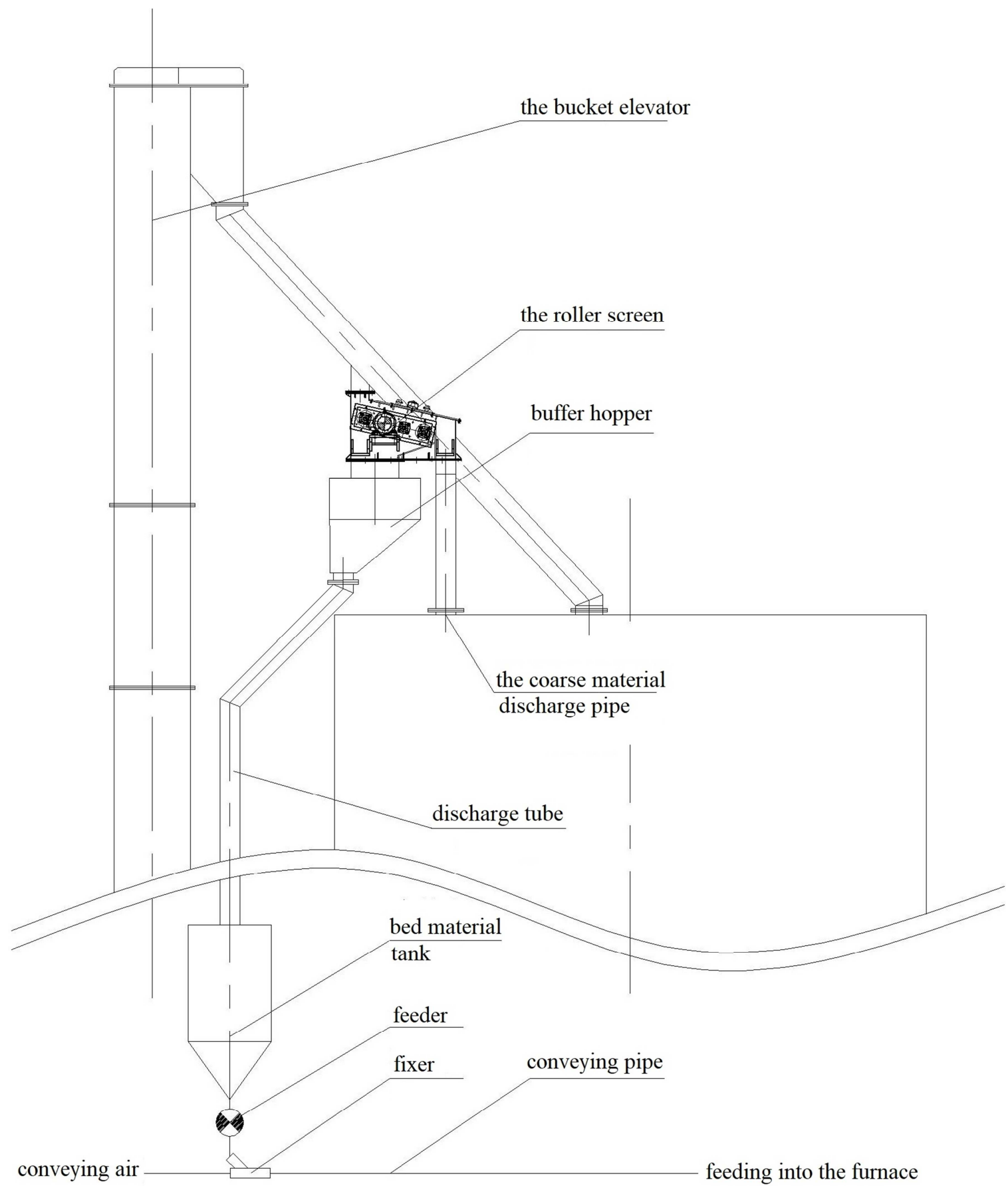

Figure 1. The system arrangement of bed slag preparation and bed material filling.

According to the layout characteristics of the bottom slag hopper elevator in this plant, the engineering design of the bed material preparation system and the bed material filling system for bottom slag is carried out, which is illustrated in Figure 1 of the bed material preparation system for bottom slag and the bed material filling system diagram. Two bucket elevators for the boiler in this plant are arranged with one for spare. The ultra-fine roller sieves for preparing bed materials are arranged between the outlet chutes of two bucket elevators, and switching valves are installed on the outlet chutes of both bucket elevators. The inlets of the roller sieves are connected through pipes. The bottom slag conveyed by the two bucket elevators can be connected to the roller sieves through the switching valves. Figure 2 is a roller sieve installed on the top of the slag silo. After the bottom slag is screened by roller, the large particles pass through the outlet of coarse material and the discharge pipe after the screen surface and fall into the slag silo; the qualified fine slag (particle size less than $3 \mathrm{~mm}$ ) is used as the bed material and falls into $0.5 \mathrm{~m}^{3}$ buffer hopper, which is stored in the bed material tank arranged near the slag silo through the pipeline, and the bed material tank is located at the $10 \mathrm{~m}$ platform of the boiler. According to the need of operation, the designed volume of the bed material tank is 2 $\mathrm{m}^{3}$, and the storage of the bed material in the bed material tank 
is mastered by setting the level gauge. The operation of the bed material preparation and filling system and the material level signal of the bed material tank are connected to the control room. The bed material preparation, filling or stopping operation can be carried out at any time according to the operation of the boiler.

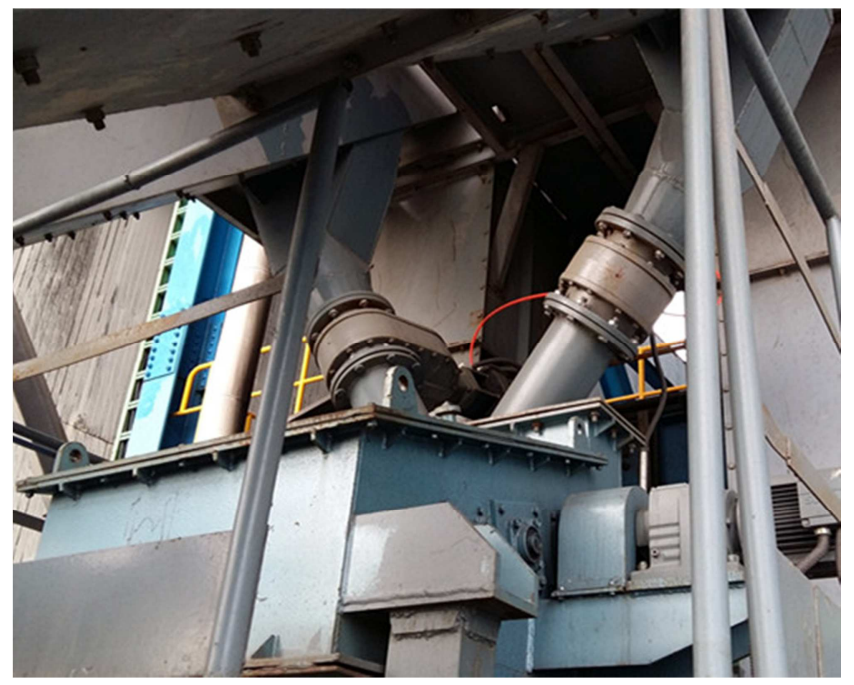

Figure 2. Ultra-fine roller screen located in the top of the slag bin.

Because the bed material system is a renovation project, the feeding port of the bed material system is shared with the feeding port of fly ash recycling system. Two sections near the fly ash recirculation feed port are transformed into three-way pipe. The two feeding ports of the three-way pipe are connected to the fly ash recirculation system and the feeding bed material system respectively, so that both the fly ash recirculation and the feeding bed material enter the furnace through the original fly ash recirculation feed port. In order to ensure the uniform distribution of feeding bed material, the feeding bed material is divided into two points, which are merged into two fly ash recirculating inlets. The bed material feeding system and fly ash recycling system can operate independently or simultaneously, so this scheme has little influence on the original equipment and operation. The conveying pipeline of this bed material filling system is only $20 \mathrm{~m}$, supplemented by the DTS conveying pipeline structure, which has the advantages of low air consumption, low resistance and high reliability.

\section{Conclusion}

In this paper, a technology of preparing qualified bed material with CFB boiler bottom slag is explored. Boiler slag is used to prepare bed material instead of quartz sand as bed material, and then be added into the fluidized bed boiler. The technology ensures the burning effect of the boiler, but also saves a large amount of purchasing cost of the bed material, reduces the discharge of the solid waste bottom of the boiler and helps to reduce the discharge of the pollutants. The limestone and the separated bed materials which have not been involved in the desulfurization reaction in the furnace are returned to the furnace together to improve the utilization ratio of the limestone powder, reduce the consumption of limestone and save the operation cost. With this preparation system, the particle size of bed material can be controlled under $3 \mathrm{~mm}$ and the combustion effect of fluidized bed is guaranteed.

The successful application of this technology provides a new type of bed material preparation and filling method with low cost, low energy consumption and good environmental protection characteristics for the industry, effectively ensures the bed material particle size and provides reliable guarantee for the combustion of circulating fluidized bed boiler. The system effectively uses the waste ash and slag, with high reliability and low operation cost, meeting the requirements of energy conservation and environmental protection, and enriches the auxiliary system of CFB boiler. It improves the supporting level of auxiliary system of CFB boiler, and further promotes the application of clean combustion fluidized bed unit.

\section{References}

[1] ZHENG Hefei. Study on the $600 \mathrm{MW}$ supercritical circulating fluidized bed boiler system [J], Energy and Energy Conservation, 2015 (12): 70-71.

[2] YUE Guangxi, LU Junfu, XU Peng, et al. The up-to-date development and future of circulating fluidized bed combustion technology [J]. Electric Power, 2016, 49 (1): 5-17.

[3] HUANG Zhong, YANG Juan, CHE Defu. Application and development of large-scale circulating fluidized bed boiler [J]. Thermal Power Generation, 2019 (6): 1-8.

[4] WANG Zhi-qiang. How to control of circulating fluidized bed boiler bed temperature [J]. Shanxi Architecture, 2013, 39 (7): 139-141.

[5] Zhao Chenyang. Importance of bed material size for circulating fluidized bed boilers [C]. Papers on Technical Exchange Service Collaboration Network of CFB Units in National Electric Power Industry, 2006, (4).

[6] SI Junlong, JI Hui. The influence of bed material size on CFB boiler operation. China Electric Power Science and Technology Network. 2009, (2).

[7] Yanjin, Lu Xiaofeng, Wang Quanhai et al. [J] Furnace test on combustion uniformity in dilute phase zone of $600 \mathrm{MW}$ supercritical CFB boiler [J]. Journal of Electrical Engineering of China. 2018, 2 (1): 64-72.

[8] ZHONG Weihong, LIU Zhaoxiang, WANG Lehua. Optimization of feeding mode for CFB boiler [J]. Electric safety technology, 2012 (8): 21-22.

[9] LIU Jinbo, LIU Yu, DU Zhengyu. The approach to the start- up material systemof CFB boiler [J]. Central China Electric Power, 2006, 19 (1): 55-58.

[10] WEN Bangchun, LIU Shuying. Modern vibration screening technology and equipment design [M]. Beijing: Metallurgical Industry Press, 2013.

[11] DL/T 1374-2014 ROLLER SCREEN [S]. 
[12] LIU Xitao. Design of Bamana -shape rolling shaft sieve and determination of main parameters $[\mathrm{J}]$. Electric Power Construction, 2000, 21 (6): 31-34.

[13] ZHAO Huanshuai. Progress and research direction of dry deep screening technology of fine grained coal $[\mathrm{J}]$. Clean Coal Technology, 2019 (5): 28-34
[14] DING Yanfeng, LI Xinsheng, JIANG Li, et al. Experimental research on the turbulence dual-tube pneumatic cinder delivery technology [J]. Electric Power, 41 (10): 53-56.

[15] ZHANG Zhanxin, Study on material and processing technology of alumina ceramic substrate [D]. Hebei: Hebei University of Technology, 2006. 